\title{
Z-contrast Imaging of Incommensurately Modulated Structure in Plagioclase Feldspars
}

\author{
Huifang $\mathrm{Xu}^{1}$, and Shiyun $\mathrm{Jin}^{1}$ \\ 1. Department of Geoscience, University of Wisconsin-Madison, 1215 W. Dayton St., Madison, \\ Wisconsin 53706, United States
}

Plagioclase feldspars $\left[\mathrm{Na}_{1-\mathrm{x}} \mathrm{Ca}_{\mathrm{x}}\left(\mathrm{Si}_{3-\mathrm{x}} \mathrm{Al}_{1+\mathrm{x}} \mathrm{O}_{8}\right)\right]$ that commonly occur in igneous and metamorphic rocks are the most abundant minerals in the earth's crust. Although crystal structures for end members of albite $\left(\mathrm{Ab}=\mathrm{NaSi}_{3} \mathrm{AlO}_{8}\right)$ and anorthite $\left(\mathrm{An}=\mathrm{CaSi}_{2} \mathrm{Al}_{2} \mathrm{O}_{8}\right)$ are relatively simple, the structures for intermediate plagioclase feldspars with incommensurate modulations are very complicated at low temperature, and are not simple mixtures of albite and anorthite subunits [1]. The crystal structures and formation mechanism of the modulated structure in intermediate plagioclase have been an enigma for decades beginning with the first discovery in 1940 [2]. The modulated structure and its formation mechanism affect our understanding about mineral associations of plagioclase feldspars and their subsolidus reactions like ordering and exsolution. All proposed structure models based on X-ray diffraction and transmission electron microscopic studies can be categorized into two groups: (1) periodic alternating lamellae with anorthite (I $\overline{1})$ structure in anti-phase relationship with a stacking vector of $1 / 2 \boldsymbol{c}$, and (2) periodic alternating lamellae with anorthite $(I \overline{1})$ and albite $(C \overline{1})$ structures.

Ca-Na ordering and structural polarity of subcells in an intermediate plagioclase with modulated structure have been observed using Z-contrast imaging methodology with an aberration-corrected scanning transmission electron microscope [3]. Neighboring lamellar domains with I1 symmetry are related by inversion twin operation, instead of anti-phase domain boundaries (or, APBs) as in all previously reported structure models. The boundaries between lamellar domains have $I \overline{1}$ symmetry instead of $C \overline{1}$ symmetry. Modulated plagioclase has unique Ca-Na and Al-Si ordering structure that is different from those in end-member structures of anorthite and low albite. The modulated structures of intermediate plagioclase are not metastable structures formed during phase transition, but rather thermodynamically stable structures at low temperature due to $\mathrm{Si}-\mathrm{Al}$ and coupled $\mathrm{Ca}-\mathrm{Na}$ ordering within the subcells with $I 1$ symmetry. The f-reflections indicate a structure with density modulation that was observed in both Ca-rich and Na-rich $e$-plagioclase feldspars $[4,5]$. The discovery of $f$-reflections in Narich $e$-plagioclase extends the composition range of $e 1$ structure with density modulation to as low as at least $\mathrm{An}_{45}$, which is below the composition range of Bøggild intergrowth. The new result supports the loop-shaped solvus for Bøggild intergrowth, below which is a homogenous stable area for $e 1$ structure in the phase diagram. The phase transition between $e 2$ structure without density modulation and $e 1$ structure with density modulation should happen at low temperature for Na-rich plagioclase feldspars. There is a change in modulation period accompanying the phase transition, as well as higher occupancy of $\mathrm{Al}$ in $\mathrm{T}_{1} \mathrm{O}$ site. The andesine with density modulation also indicates extremely slow cooling history.

\section{References:}

[1] Smith, J. V. \& Brown, W. L. (1988). Feldspar Minerals. Berlin Heidelberg: Springer-Verlag.

[2] Chao, S. H. \& Taylor, W. H. (1940). Proc. Roy. Soc. London A, pp. 76-87.

[3] Xu, H. (2015). Am Mineral 100, 510-515. 
[4] Jin, S. \& Xu, H. (2017). American Mineralogist, 102, 21-32.

[5] Xu, H., Jin, S., and Noll, B. C. (2016) Acta Crystallographica, B72, 904-915.
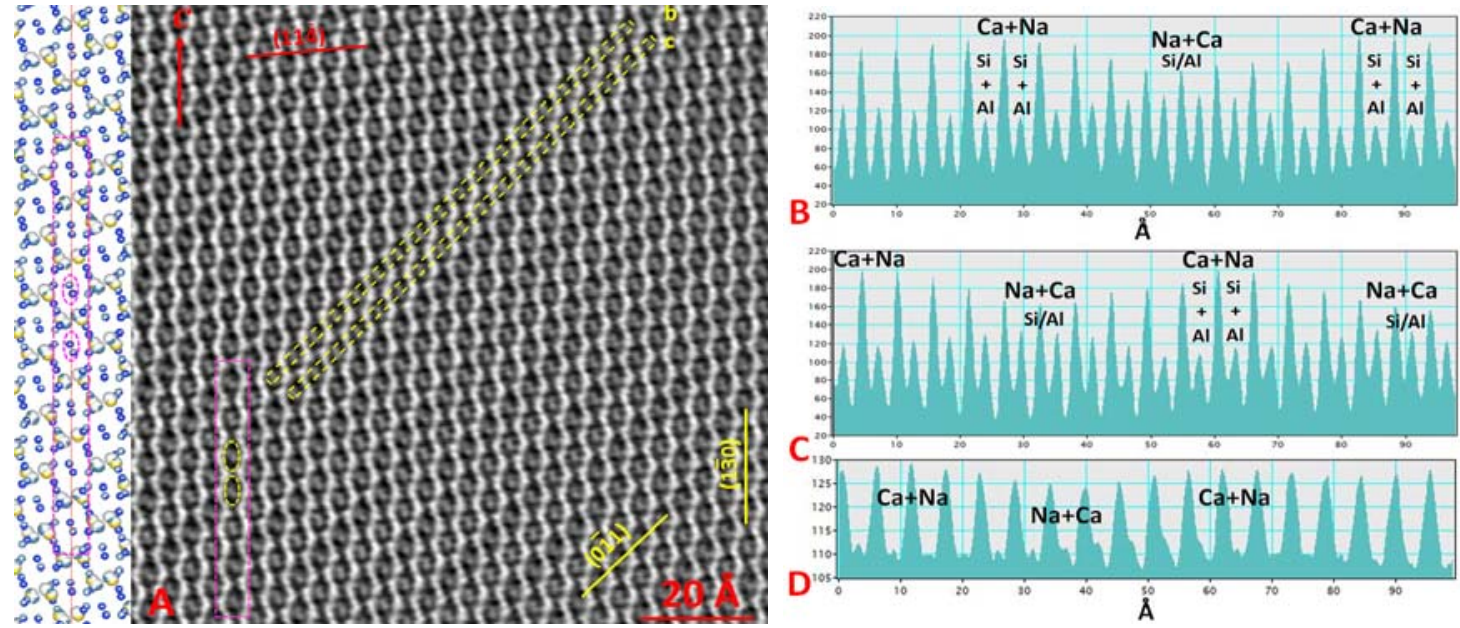

Figure 1 (A) Noise-filtered Z-contrast image showing structural modulation in a Na-rich plagioclase through orientation changes of neighboring Si/Al dumbbells (outlined with yellow ovals) and framework. A section of the structure from structural refinement is also illustrated at the left side of the image. (B) Intensity profile from an outlined "b" cross section of part of the subcell showing the modulation wave. (C) Intensity profile from an outlined "c" cross section that is next to "b", also showing the modulation wave. (D) Average intensity profile of whole unit cell showing total intensity variation due to density modulation.

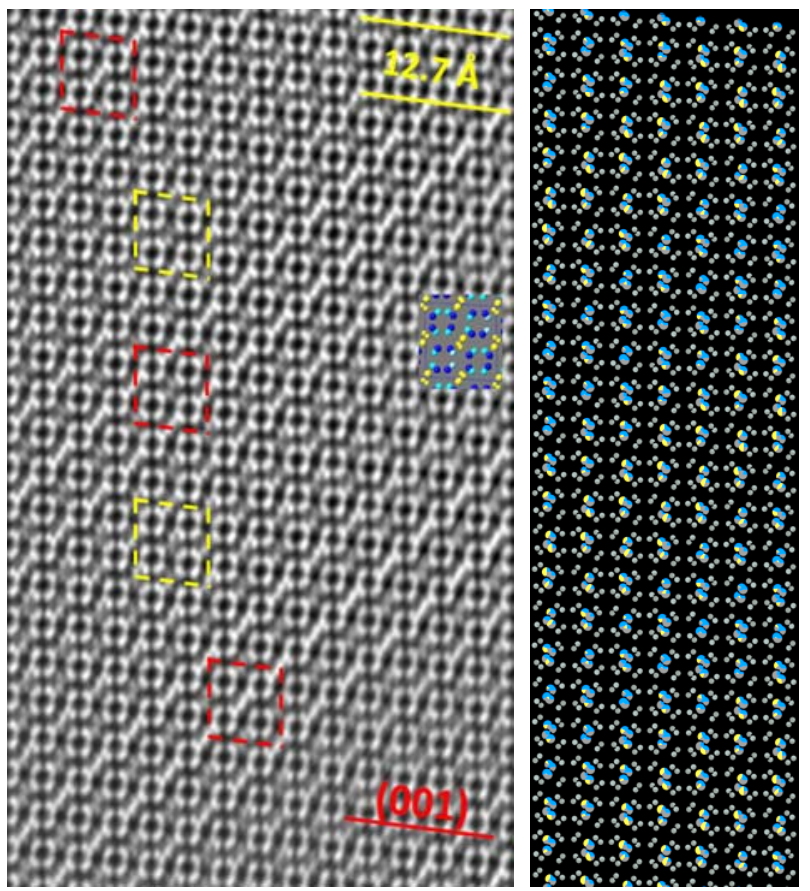

Figure 2. Noise-filtered Z-contrast image of a Ca-rich plagioclase clearly showing Ca-Na ordering in lamellae domains and at the inversion boundary positions. Neighboring lamellae domains with I1symmetry are in inversion twin relationship. A unit cell structure model showing polarity of $\mathrm{Na}-\mathrm{Ca}$ atoms is also overlaid on the image. A section of the structure from single-crystal XRD structural refinement is also illustrated at the center (with black background) and right side (with white background) of the figure. Both the image and structure refinement result match well. 